\title{
Raindrop Influence on the Soil Surface ${ }^{\dagger}$
}

\author{
Martin Neumann 1,*, David Zumr 1, Petr Kavka 1, Tomáš Dostál 1, Tomáš Laburda ", Michal Vrána 1, \\ Nives Zambon ${ }^{2}$, Lisbeth Lolk Johannsen ${ }^{2}$, Peter Strauss ${ }^{3}$ and Andreas Klik ${ }^{2}$ \\ 1 Faculty of Civil Engineering, Czech Technical University in Prague, 16636 Praha 6, Czech Republic; \\ david.zumr@fsv.cvut.cz (D.Z.); petr.kavka@fsv.cvut.cz (P.K.); dostal@fsv.cvut.cz (T.D.); \\ tomas.laburda@fsv.cvut.cz (T.L.); michal.vrana@fsv.cvut.cz (M.V.) \\ 2 Institute for Soil Physics and Rural Water Management, University of Natural Resources and Life Sciences, \\ 1190 Vienna, Austria; nives.zambon@boku.ac.at (N.Z.); lisbeth.johannsen@boku.ac.at (L.L.J.); \\ andreas.klik@boku.ac.at (A.K.) \\ 3 Federal Agency for Water Management, Institute for Land \& Water Management Research, \\ 3252 Petzenkirchen, Austria; peter.strauss@baw.at \\ * Correspondence: martin.neumann@fsv.cvut.cz \\ † Presented at TERRAenVISION 2019, Barcelona, Spain, 2-7 September 2019.
}

Published: 19 May 2020

\begin{abstract}
Soil erosion through various water processes is a worldwide problem. This research is focused on raindrops' impact on soil surfaces, which is generally considered the initial stage of the erosion process. Splash erosion monitoring was conducted across three experimental sites: Petzenkirchen, Mistelbach (Austria) and Prague (Czech Republic). At each site, the rainfall characteristics (intensity and kinetic energy) were measured by rain gauges and disdrometers, and the impacts on soils (soil loss, soil surface consolidation, changes in soil surface roughness) were evaluated. Several disturbed soil samples with an area of $78.5 \mathrm{~cm}^{2}$ were placed into splash cups prior to each event. The splash cup collects the soil particles that are splashed out of the sample area when a raindrop hits the soil surface. The collected sediment suspension is processed in the laboratory after each event to determine the lost soil mass. Ground photogrammetry was utilized to determine the surface consolidation of a sample caused by a given rainfall event. Results for more than 500 soil samples were included in this study. Relationships between kinetic energy, rainfall intensity and soil loss and consolidation were evaluated.
\end{abstract}

Keywords: rainfall; kinetic energy; soil loss; splash erosion

Acknowledgments: This research has been carried out within the framework of projects SGS17/173/OHK1/3T/11 GA17-33751L; and FWF I 3049-N29.

(C) 2020 by the authors. Licensee MDPI, Basel, Switzerland. This article is an open access article distributed under the terms and conditions of the Creative Commons Attribution (CC BY) license (http://creativecommons.org/licenses/by/4.0/). 